\title{
Microvascular Endothelial Cell Responses in vitro and in vivo: Modulation by Zoledronic Acid and Paclitaxel?
}

\author{
Maria Michailidou $^{a}$ Hannah K. Brown ${ }^{a}$ Diane V. Lefley ${ }^{a}$ Alyson Evans $^{a}$ \\ Simon S. Cross ${ }^{c}$ Robert E. Coleman ${ }^{a}$ Nicola J. Brown ${ }^{b}$ Ingunn Holen ${ }^{a}$ \\ Academic Units of a Clinical Oncology, ${ }^{b}$ Surgical Oncology and ${ }^{\mathrm{c} P a t h o l o g y, ~ S c h o o l ~ o f ~ M e d i c i n e ~ a n d ~ B i o m e d i c a l ~}$ \\ Sciences, University of Sheffield, Sheffield, UK
}

\section{Key Words}

Anti-angiogenic therapy $\cdot$ Anti-vascular therapy $\cdot$ Dorsal microcirculation chamber $\cdot$ Endothelial cells $\cdot$ Paclitaxel $\cdot$ Zoledronic acid

\begin{abstract}
Background/Aims: The cytotoxic agent paclitaxel and the anti-resorptive drug zoledronic acid are used in the early and advanced breast cancer setting, respectively. Both agents have been demonstrated to have anti-tumour and anti-endothelial actions. Combining paclitaxel with zoledronic acid induces a synergistic increase in apoptotic breast cancer cell death in vitro, suggesting an increased anti-tumour effect in vivo, but any specific effects on the normal microvasculature and potential side-effects of this combination remain to be established. Methods: The effects of zoledronic acid and paclitaxel were investigated, alone and in combination, on human microvascular endothelial cells in vitro, using functional assays including proliferation, migration, tubule formation and apoptosis. The in vivo effect of the drugs on the normal microvasculature was determined using the dorsal microcirculation chamber model. Results/Conclusion: Zoledronic acid reduced human dermal microvascular endothelial cell (HuDMEC) proliferation, caused accumulation of cells in S phase, and inhibited migration, tube formation and Rap1a prenylation. Paclitaxel significantly inhibited tube for-
\end{abstract}

\section{KARGER}

Fax +41613061234 E-Mail karger@karger.ch www.karger.com

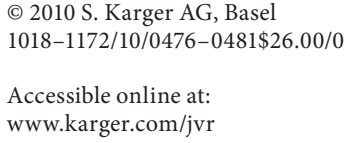

mation and proliferation, and increased endothelial necrosis; the combination induced HuDMEC apoptosis and further enhanced the inhibition of tube formation and migration. The combination caused minimal effects on the normal microvasculature in vivo, suggesting that this potential therapeutic strategy is not associated with deleterious microvascular side-effects.

Copyright $\odot 2010$ S. Karger AG, Basel

\section{Introduction}

Over the past decade there has been an increasing research effort to develop inhibitors of tumour angiogenesis as anti-cancer therapies. Tumours up to $\sim 1 \mathrm{~mm}$ in diameter obtain oxygen and nutrients by passive diffusion. Small tumour cell populations subsequently stimulate the angiogenic switch, recruiting endothelial cells (EC) from surrounding tissues, as well as endothelial progenitor cells that home from the bone marrow to the site of active angiogenesis via the circulation. This leads to the formation of a new vascular network that infiltrates and nourishes the tumour mass, facilitating tumour expansion.

\section{N.J.B. and I.H. are joint senior authors.}

Dr. Ingunn Holen

Academic Unit of Clinical Oncology

DU 19, School of Medicine and Biomedical Sciences, University of Sheffield Beech Hill Road, Sheffield S10 2RX (UK)

Tel. +44 114271 3854, Fax +44 114271 1711, E-Mail i.holen@ sheffield.ac.uk 
Anti-angiogenic agents may inhibit expansion of the tumour mass, or induce growth suppression to a pre-angiogenic volume, which may be further reduced by administration of chemotherapy. Conventional anti-cancer therapies, such as cytotoxic drugs [1-4] and anti-resorptive agents [5], may also affect the tumour microvasculature. Zoledronic acid is used in the treatment of cancerinduced bone disease [6], and has been shown to have anti-tumour effects both in vitro [5] and in metastasis models in vivo $[5,7,8]$. Anti-angiogenic effects of zoledronic acid have been demonstrated on EC in vitro [9], and in vivo there is reduced angiogenic growth factorinduced vascularisation of normal tissue or subcutaneous implants $[9,10]$. In addition, zoledronic acid reduces the levels of circulating angiogenic factors, such as vascular endothelial, platelet-derived [11] and basic fibroblast growth factors [12], in patients with advanced cancer [11]. Previous studies have shown that the anti-tumour effect of zoledronic acid in vitro is enhanced when administered in a specific sequence with the cytotoxic agent paclitaxel $[13,14]$

Paclitaxel is a cytotoxic agent that disrupts normal microtubule function, causing accumulation of the cells in the G2/M phase ultimately leading to apoptotic cell death [15]. Studies have shown that paclitaxel interferes with the microtubule network of EC [16] at concentrations lower than those required to affect tumour cells, but without inducing apoptotic EC death $[3,17]$. Anti-angiogenic properties of both zoledronic acid and paclitaxel have been described, but the majority of studies have used macrovascular EC, e.g. human umbilical vein EC (HUVEC) rather than microvascular EC. Previous in vitro studies have generally used high concentrations of zoledronic acid and paclitaxel to generate anti-angiogenic effects compared to the clinically achievable doses $[3,9,17$, 18]. Although both drugs may be used in the treatment of advanced breast cancer they are not routinely administered in combination and are often given some time apart. There is no information on potential vascular sideeffects associated with combining the two agents, and no previous studies have investigated the effects on the normal microvasculature following co-administration of paclitaxel and zoledronic acid in vivo, an important indicator of potential adverse effects associated with combination therapy.

In this study, we investigated the effects of zoledronic acid and paclitaxel, alone and in combination, on human dermal microvascular EC (HuDMEC) in vitro, followed by in vivo studies determining responses on the normal microvasculature using the dorsal microcirculation chamber (DMC) model. Our data show that the combination of paclitaxel and zoledronic acid increases inhibition of HuDMEC migration, apoptosis and tubule formation in vitro compared to administration of the single agents. Microvascular diameters remained unchanged in the DMC, with no evidence of endothelial disruption in other normal tissues on histological analysis, following in vivo administration of the combination regime. This suggests that zoledronic acid and paclitaxel may not cause adverse short-term (up to 5 days) damage on the normal microvasculature if used as a combination therapy.

\section{Methods}

\section{Cell Culture}

HuDMEC were extracted from excess tissue following routine breast surgery (kindly provided by Prof. M.W.R. Reed, Royal Hallamshire Hospital, Sheffield, UK; Ethics No. SSREC98/198). All patients gave written informed consent for the use of their tissue for research. HuDMEC were isolated using CD31 Dynabead ${ }^{\circledR}$ selection (Invitrogen, UK) to ensure a homogenous population and cultured in EBM-2 containing 5\% v/v of foetal bovine serum with supplements (standard culture medium; Cambrex, UK) at $37^{\circ} \mathrm{C}$ and $5 \% \mathrm{CO}_{2}$. Cells were used between passages 3 and 7 , with approximately 20 different cell isolates used in the study.

\section{Drugs}

Zoledronic acid [1-hydroxy-2-( ${ }^{1} \mathrm{H}$-imidazol-1-yl)ethylidene] bisphosphonic acid (supplied as the hydrated disodium salt by Novartis Pharma AG, Switzerland) was diluted in phosphatebuffered saline (PBS). For in vitro use, paclitaxel (Sigma, UK) was dissolved in DMSO at $10 \mathrm{~mm}$ according to the manufacturer's instructions and then diluted to $1 \mathrm{mM}$ in PBS. For the experiments nanomolar concentrations were used hence the final DMSO concentration is approximately $10^{-6} \mathrm{M}$. For in vivo use paclitaxel was diluted in 1:1 anhydrous ethanol:Cremophor EL $(\mathrm{BDH}, \mathrm{UK})$. Drug dilutions were sterile filtered using Acrodisk ${ }^{\circledR}$ syringe filters $0.8 / 0.2 \mu \mathrm{m}$ (Pall, UK) before use. The final concentrations used for the combination experiments were based on preliminary dose-response and time-course studies performed for each of the assays allowing us to establish the doses of each agent that produced no greater than 50\% inhibition. Wherever feasible, the observer analysing the data was blinded to the treatment groups.

\section{Cell Cycle Analysis}

HuDMEC were cultured in T25 flasks (Nunc, UK) under standard conditions until approximately $20 \%$ confluent and washed with PBS before addition of drugs. To determine the effect of zoledronic acid on $S$ phase, cells were treated with 25 or $50 \mu \mathrm{M}$ zoledronic acid for $24-72 \mathrm{~h}$. In the combined treatment, cells were incubated for $24 \mathrm{~h}$ with $25 \mu \mathrm{M}$ zoledronic acid and $4 \mathrm{nM}$ paclitaxel, followed by 48 -hour incubation in drug-free standard culture medium. Floating and adherent cells were harvested and centrifuged to remove the supernatant. HuDMEC were resuspended 
in $2 \mathrm{ml}$ PBS, then pelleted, fixed by dropwise addition of $1 \mathrm{ml}$ of $70 \%$ ice-cold ethanol and incubated at $4{ }^{\circ} \mathrm{C}$ overnight. For cell cycle analysis, cells were washed twice in $1 \mathrm{ml}$ of PBS and resuspended in $50 \mu \mathrm{g} / \mathrm{ml}$ propidium iodide and $100 \mu \mathrm{g} / \mathrm{ml}$ RNase A (Sigma). Following overnight incubation at $4^{\circ} \mathrm{C}$, cell cycle analysis was performed using an FACSort analyser (BD Biosciences, UK) and the CellQuest (BD Biosciences) software programme was used to plot flow charts and to quantify the results using the parameters FL3 ( $\mathrm{x}$-axis, which represents the signal value of the parameter) and FL1 (y-axis, which represents the number of events of the parameter). The experiment was carried out three times in triplicate.

\section{Cell Proliferation}

HuDMEC were seeded into 24 -well plates at $10^{4}$ cells/well and incubated overnight at $37^{\circ} \mathrm{C}$ and $5 \% \mathrm{CO}_{2}$. Following washing with PBS, 1, 10, 25 and $50 \mu \mathrm{M}$ zoledronic acid (24, 48 and $72 \mathrm{~h}$ ) or 2, 4 and $10 \mathrm{nM}$ paclitaxel (48 and $72 \mathrm{~h}$ ) were added to the standard culture medium, and cells were counted after 24,48 and $72 \mathrm{~h}$ of incubation using a Coulter Counter (Becton-Dickinson, UK). The experiment was carried out three times in triplicate.

\section{Cell Death Assay: Apoptosis and Necrosis}

Following treatment with $50 \mu \mathrm{M}$ zoledronic acid and $2 \mathrm{nM}$ paclitaxel for $24 \mathrm{~h}$ with 48 -hour incubation in drug-free medium, HuDMECs were incubated with $8 \mu$ M Hoechst 33342 (Sigma RBI, $\mathrm{UK}$ ) and $5 \mu \mathrm{M}$ propidium iodide (Molecular Probes, UK) in the dark for $15 \mathrm{~min}$ at $37^{\circ} \mathrm{C}$ and $5 \% \mathrm{CO}_{2}$. Detection of cell death was performed by manual counting of necrotic (propidium iodide positive), viable and apoptotic (Hoechst $33342+$ ) nuclei, the apoptotic nuclei displaying features of karyorrhexis. Evaluation of nuclear characteristics was made using an inverted fluorescentphase Leica DMIRB microscope with an UV filter (355 nm excitation and $465 \mathrm{~nm}$ emission). The numbers of viable, apoptotic and necrotic cells were determined by manual counting using a Whipple graticule (100 squares in a 7- $\mathrm{mm}^{2}$ area from Pyser-SGI, UK). The percentage of each type of cell death was established by counting 5 different areas per well. Each experiment was carried out three times and included quadruplicate samples.

\section{Detection of Unprenylated Rap1a}

HuDMEC were cultured in T25 flasks under standard conditions and treated with 10-50 $\mu \mathrm{M}$ of zoledronic acid for 24,48 and $72 \mathrm{~h}$. HuDMEC lysates were generated using a mammalian cell lysis kit (Sigma) according to the manufacturer's instructions, and $10 \mu \mathrm{g}$ of cell lysate and $10 \mu \mathrm{l}$ of molecular weight marker (BioRad, UK) were loaded in each lane of a $10 \%$ polyacrylamide-SDS gel, followed by blotting onto polyvinylidene difluoride membranes (PVDF Immobilisation Transfer Membranes; Millipore, UK) under reducing conditions. Membranes were then incubated with goat polyclonal antibody specific for unprenylated Rapla (1:2,000, Cat. No. sc1482, clone C-17; Santa Cruz Biotechnology, USA) in blocking buffer ( $5 \%$ dried milk in distilled water) at $4^{\circ} \mathrm{C}$ overnight, followed by a 1-hour incubation with anti-rabbit IgGHRP conjugate in blocking buffer (1:15,000, Cat. No. NA934; Amersham Biosciences, UK). The protein bands were visualised using Supersignal West Dura (Pierce, UK) and developed on Kodak Biomax MR film (Anachem, UK). Each experiment was performed three times.

Anti-Vascular Effects of Zoledronic Acid and Paclitaxel

\section{Tube Formation Assay}

HuDMEC were pre-treated in T25 flasks with $10 \mu \mathrm{M}$ zoledronic acid for $24 \mathrm{~h}$ and $0.25 \mathrm{nM}$ paclitaxel for $4 \mathrm{~h}$, with further 48-hour incubation in drug-free culture medium. Cells were trypsinised and transferred onto 24-well plates coated with full growth factor Matrigel ${ }^{\circledR}(30 \mu \mathrm{l} \mathrm{Matrigel/well,} \mathrm{BD} \mathrm{Biosciences)} \mathrm{at}$ $2 \times 10^{4}$ cells/well, including a control of untreated cells, followed by incubation at $37^{\circ} \mathrm{C}$ and $5 \% \mathrm{CO}_{2}$ for $8 \mathrm{~h}$, fixed with ice-cold ethanol and stained with haematoxylin (BDH) for $5 \mathrm{~min}$ followed by eosin (BDH) for $2 \mathrm{~min}$. Tubules were photographed in 3 randomly chosen fields of view per well using a $\times 4$ objective, and their number manually determined. Tubules assessed in this study could be defined as belonging to one of the three following categories: (1) intercellular tubule: a single tube formed between two single cells; (2) 'chain-like' tubule: tubes formed by multiple single cells arranged in a row connecting two cell 'islands', and (3) 'bridge-like' tubule: tubes formed by two tube chains arranged in a thick bundle that connects two cell 'islands'. Each experiment was performed three times in quadruplicate.

\section{Migration Assay}

HuDMEC were seeded in 6-well plates pre-coated with $0.2 \%$ gelatin at $6.6 \times 10^{5}$ cells/well, and incubated overnight at $37^{\circ} \mathrm{C}$ and $5 \% \mathrm{CO}_{2}$. HuDMEC were then incubated with $10 \mu \mathrm{g} / \mathrm{ml} /$ well of mitomycin C (Sigma) in serum-free RPMI for $3 \mathrm{~h}$ on ice to inhibit cell proliferation during the migration period, followed by a $20-\mathrm{min}$ recovery incubation in standard culture medium at $37^{\circ} \mathrm{C}$ and $5 \%$ $\mathrm{CO}_{2}$. Two 1-mm scratches/well were made and two fields of view/ scratch were marked on the external lower surface of the plate to indicate the exact position for the assessment of migration. HuDMEC were then thoroughly washed with PBS before $50 \mu \mathrm{M}$ zoledronic acid and $500 \mathrm{pM}$ paclitaxel were added to standard culture medium for $48 \mathrm{~h}$. Following marking of the cell-free area, migration was determined as percentage of scratch closure, quantified by use of Image J software (National Institutes of Health, USA). The experiment was carried out three times in quadruplicate.

\section{Animals and DMC Implantation}

Male CD1 nude mice ( 8 weeks old, $\mathrm{n}=19$ ) were obtained from Charles River Laboratories (UK). Housing, handling, and surgical and treatment procedures were conducted in accordance with Home Office UK legislation under PPL 40/2972 (N.J.B.). DMC was manufactured from titanium by the Medical Workshops (University of Sheffield, UK). DMC consists of a pair of window frames, a pair of C-clips, a pair of glass slips ( $\varnothing 8 \mathrm{~mm}), 3$ screws, 3 nuts and 3 spears. Mice were anaesthetised with $150 \mu \mathrm{l}$ of 1:1 Hypnorm (VetaPharma, UK)/diazepam (Alpharma, UK) in two parts of water (Braun, Germany). A circular section of dermis and the most superficial layer of the panniculus carnosus muscle with underlying fascia was removed from one side of the dorsal skin flap, which allowed recording of microvessels on the contralateral side. The two chamber halves were sutured onto each side of the skin flap, filled with saline, sealed with a circular glass slide and secured with a titanium clip [19].

Administration of Zoledronic Acid and Paclitaxel in vivo

Mice were allowed to recover from surgery for approximately $36 \mathrm{~h}$ prior to drug administration. Before surgery the animals were trained to sit in a Plexiglas restrainer mounted onto the microscope, 


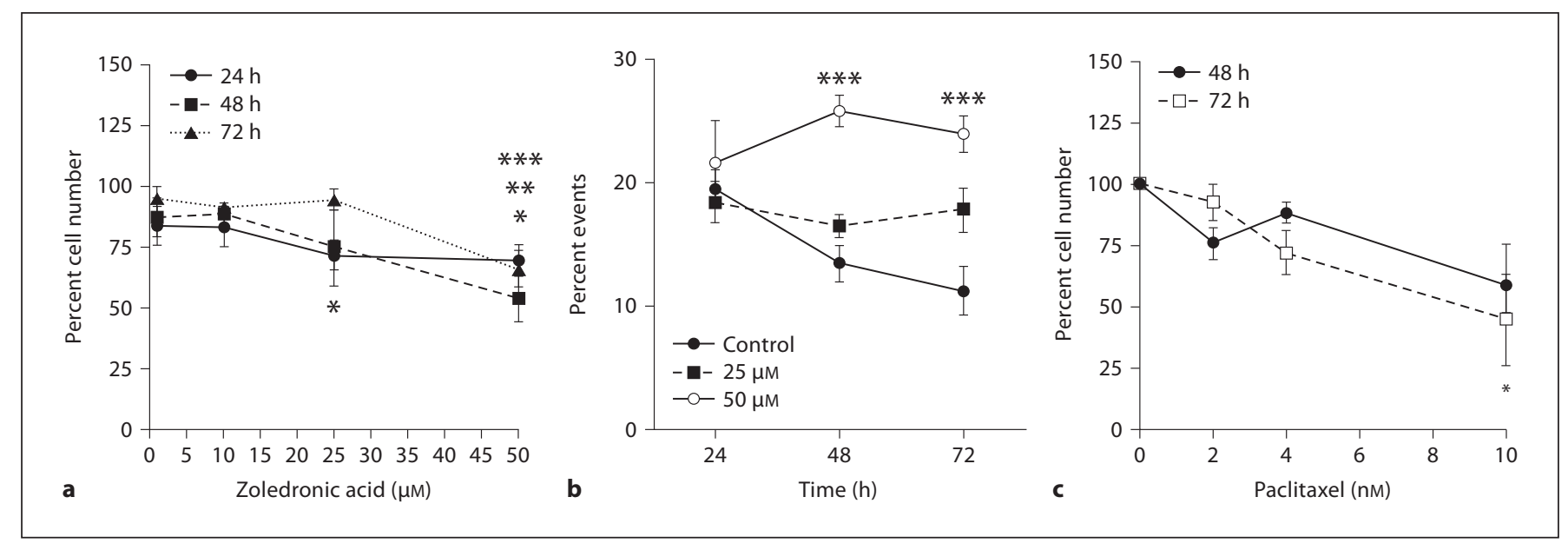

Fig. 1. Effects of zoledronic acid and paclitaxel on HuDMEC proliferation and cell cycle. a The effect of zoledronic acid on HuDMEC proliferation. HuDMEC were treated with 1-50 $\mu \mathrm{M}$ of zoledronic acid for 24-72 h. Data were normalised against untreated control and presented as percentage of cell number against increasing concentration $\left({ }^{*} \mathrm{p}<0.05 ;{ }^{* *} \mathrm{p}<0.01\right.$; $\left.{ }^{* *} \mathrm{p}<0.001\right)$. b The effect of zoledronic acid on accumulation of HuDMEC in $S$ phase. HuDMEC were treated with 25 and $50 \mu \mathrm{M}$ of zoledronic acid for 24-72 h. Data are presented as percentage of cell number in $S$ phase against total percentage of events in $S$ phase with increasing time $\left({ }^{*} \mathrm{p}<0.05 ;{ }^{*} \mathrm{p}<0.01 ;{ }^{* *} \mathrm{p}<0.001\right)$. c The effect of paclitaxel on HuDMEC proliferation. HuDMEC were treated with 2-10 nM of paclitaxel for 48 and $72 \mathrm{~h}$. Data were normalised against untreated control and presented as percentage of cell number against increasing concentration $\left({ }^{*} \mathrm{p}<0.05\right)$. a-c Error bars indicate $\pm \operatorname{SEM}(\mathrm{n}=3)$. which minimised any effects on the microvasculature due to stress. The horizontally mounted microscope (Nikon, UK) was connected to a video recorder and 30 -second recordings of the microvasculature were taken from 3 randomly selected arterioles and venules per animal [19]. The same vessels were monitored at each time point following drug administration, and then again on each individual day of treatment. On days of drug administration, a 30-second video recording was taken before treatment (baseline), and immediately following treatment at $0 \mathrm{~min}$, at $30 \mathrm{~min}$ and finally at $120 \mathrm{~min}$. Each arteriolar and venular diameter was determined in triplicate along a $30-\mu \mathrm{m}$ length of vessel at each time point, using CapiScope image analysis software (KK Technologies, UK). Three administration schedules were used: (A) zoledronic acid alone - administered intraperitoneally at 50,100 and $150 \mu \mathrm{g} / \mathrm{kg}$ once per day (days 1,3 and 5; $\mathrm{n}=8) ;(\mathrm{B})$ paclitaxel alone - administered at 10, 20 and 30 $\mathrm{mg} / \mathrm{kg}$ i.p. once per day (days 1, 3 and 5; $\mathrm{n}=5$ ), and (C) zoledronic acid combined with paclitaxel. Zoledronic acid was administered at $100 \mu \mathrm{g} / \mathrm{kg}$ i.p. with $20 \mathrm{mg} / \mathrm{kg}$ i.v. paclitaxel on day 1 , followed by 20 $\mathrm{mg} / \mathrm{kg}$ i.v. paclitaxel on days 3 and $5(n=6)$. The regimes reflect the clinical administration of these agents. Animals were killed by schedule 1 at the end of the study and tissues removed for morphological and histological assessment.

\section{Histological Assessment of EC Morphology}

Evaluation of whether the treatments caused overt disruption of EC barriers or acute toxicity, in addition to the morphology of the endothelium and microvasculature, were assessed in a separate experiment, using the combination therapy protocol but without DMC implantation. After culling, brain, spleen, lungs and liver were isolated from 2 animals from each treatment group. Tissues were fixed, paraffin embedded and processed for histo- logical analysis using standard methodology. Sections were stained using a rat antibody specific for mouse CD34 (MCA1825CA 1:50, ABDSerotec, UK) and an IgG2A isotype control, EC and vessel morphology were assessed by an experienced histopathologist (S.S.C.) who was blinded to the treatment groups.

\section{Statistical Analysis}

Statistical analysis was carried out by GraphPad Prism (version 5.00) for Windows (GraphPad Software, USA) with 95\% confidence intervals. For in vitro studies, dose- and time-response data with zoledronic acid and the migration study were analysed by two-way ANOVA with Bonferroni post hoc test. Proliferation data using paclitaxel, and apoptosis and tube formation data were analysed by Kruskal-Wallis test with Dunns post hoc test. Cell cycle data using combined treatment were analysed by KruskalWallis test with Bonferroni post hoc test. For in vivo studies, data with single agents were analysed by Kruskal-Wallis test with Dunn's post hoc test, combined treatment was analysed by twoway ANOVA with Bonferroni post hoc test. $\mathrm{p}<0.05$ was considered statistically significant.

\section{Results}

\section{Effects of Zoledronic Acid and Paclitaxel on HuDMEC Proliferation and Cell Cycle}

It remains to be established how zoledronic acid affects HuDMEC proliferation, and whether this is associated with induction of apoptosis. We therefore deter- 


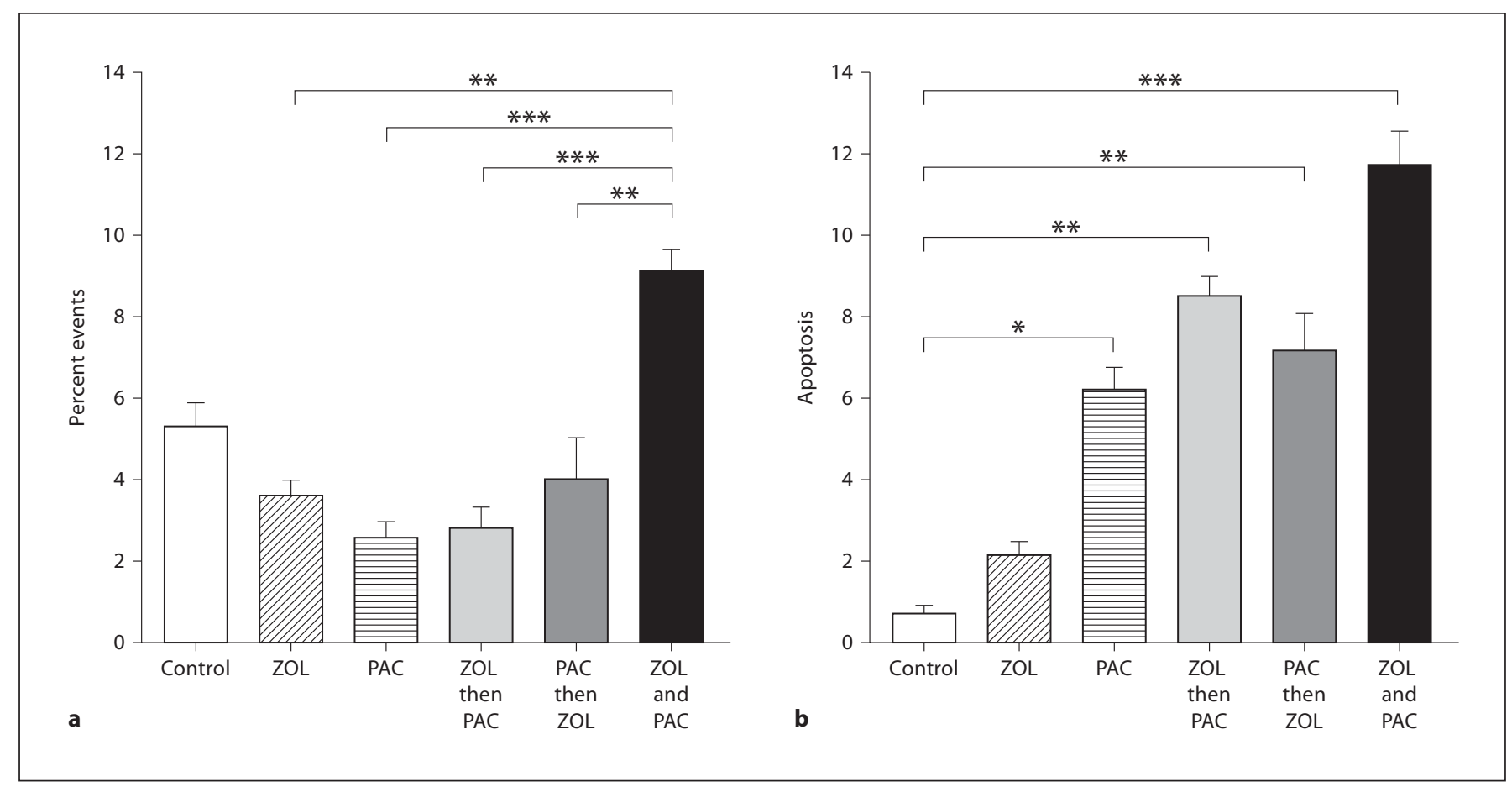

Fig. 2. The effect of combined treatment with zoledronic acid (ZOL) and paclitaxel (PAC) on accumulation of HuDMEC in $S$ phase and induction of apoptosis. Error bars indicate \pm SEM ( $\mathrm{n}=$ 3). a HuDMEC were treated with $25 \mu \mathrm{M}$ of zoledronic acid and $4 \mathrm{nM}$ of paclitaxel for $24 \mathrm{~h}$, followed by a 48 -hour incubation in drug-free culture medium. Percentage of cells (percent events) accumulated in $S$ phase was detected by flow cytometry. ${ }^{* *} \mathrm{p}<0.01$ ${ }^{* * *} \mathrm{p}<0.001$, vs. untreated control per incubation time point. b The effect of combined treatment with zoledronic acid and paclitaxel on EC apoptosis. HuDMEC were treated with $50 \mu \mathrm{M}$ zoledronic acid and $2 \mathrm{nM}$ paclitaxel sequentially or simultaneously combined for $24 \mathrm{~h}$, followed by a 48 -hour incubation in drug-free standard cell culture medium. Apoptosis was determined by evaluation of nuclear morphology using UV light microscopy. ${ }^{*} \mathrm{p}<$ $0.05 ;{ }^{* *} \mathrm{p}<0.01 ;{ }^{* *} \mathrm{p}<0.001$, vs. all treatments. mined the effect of zoledronic acid (1, 10, 25 and $50 \mu \mathrm{M})$ on HuDMEC proliferation and cell cycle progression, following treatment for 24,48 and $72 \mathrm{~h}$ (fig. 1a). Zoledronic acid $(25 \mu \mathrm{M})$ inhibited cell proliferation after 24 $\mathrm{h}$ of treatment to $28.3 \pm 6.3 \%$ ( $\mathrm{p}<0.05)$ and $50 \mu \mathrm{M}$ to $30.7 \pm 17.1 \%(\mathrm{p}<0.05)$ compared to untreated cells. Longer incubation periods with $50 \mu \mathrm{M}$ zoledronic acid did not cause an additional reduction in proliferation, with $46.3 \pm 9.2 \%(\mathrm{p}<0.001)$ at $48 \mathrm{~h}$ and $34.0 \pm 7.4 \%$ $(\mathrm{p}<0.01)$ at $72 \mathrm{~h}$ compared to untreated cells. This decrease in cell proliferation was accompanied by an increased accumulation of cells in S phase of the cell cycle, with $50 \mu \mathrm{M}$ zoledronic acid for $48 \mathrm{~h}(12.4 \pm 1.3 \%$; $\mathrm{p}<$ $0.001)$ and $72 \mathrm{~h}(12.7 \pm 5 \% ; \mathrm{p}<0.001)$ compared to untreated cells (fig. 1b), with a corresponding decrease in cell number in G1 and G2/M phases, but there was no induction of apoptotic cell death (data not shown). Paclitaxel (0.01-10 nM) has been shown to affect HUVEC proliferation $[16,20]$, whereas effects on HuDMEC have not been reported. Paclitaxel caused a dose-dependent inhibition of HuDMEC proliferation, with maximal effects at $10 \mathrm{nM}$ for $72 \mathrm{~h}(44.8 \pm 18.6 \%$; $\mathrm{p}<0.05$ vs. control, fig. 1c).

\section{Combining Zoledronic Acid and Paclitaxel Induces \\ HuDMEC Apoptosis and Increases Accumulation of \\ S-Phase Cells}

We next determined whether combining paclitaxel and zoledronic acid modulated EC cycle distribution and apoptosis levels, following treatment with either the single agents, or the drugs given in sequence or simultaneously. Simultaneous treatment with $25 \mu \mathrm{M}$ of zoledronic acid and $4 \mathrm{nM}$ of paclitaxel attenuated HuDMEC cycle at $S$ phase $(10.1 \pm 0.3 \%)$ compared with zoledronic acid alone $(3.99 \pm 0.3 \%$; $p<0.01)$, paclitaxel alone $(2.6 \pm$ $7.7 \%$; $<<0.001)$ or the sequential treatment of zoledronic acid followed by paclitaxel $(2.8 \pm 0.5 \% ; \mathrm{p}<0.001)$ and paclitaxel then zoledronic acid $(4.0 \pm 1.0 \% ; \mathrm{p}<0.01$; 


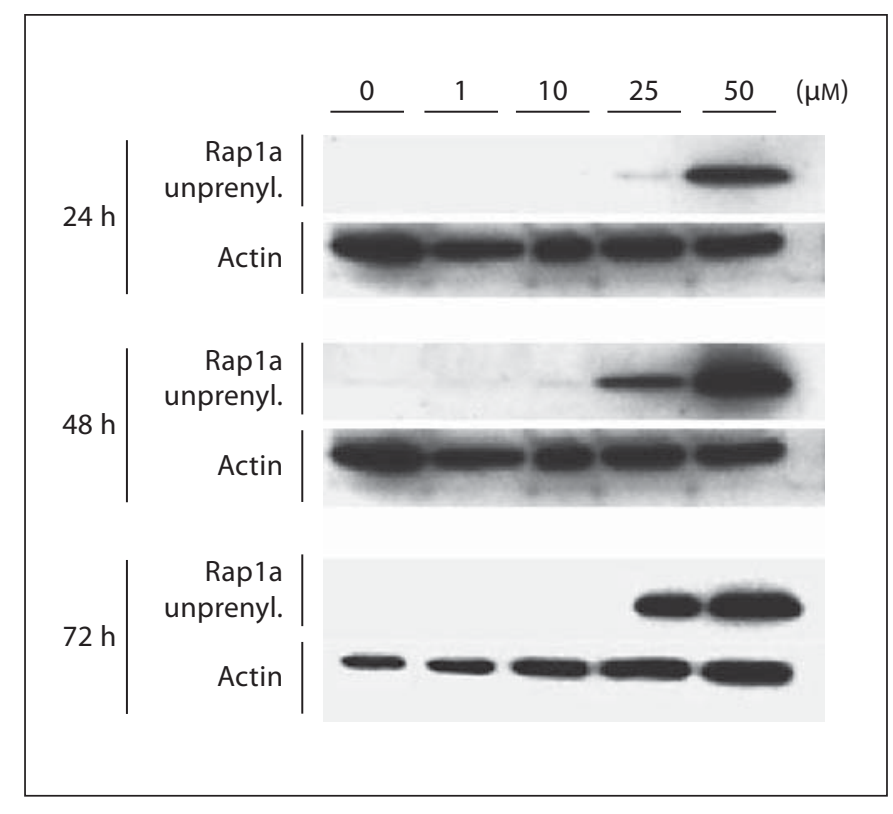

Fig. 3. The effect of zoledronic acid on prenylation of Rapla. HuDMEC were treated with 10-50 $\mu \mathrm{M}$ zoledronic acid for 24, 48 and $72 \mathrm{~h}$ and unprenylated Rapla levels were determined by Western blot using an antibody specific for unprenylated Rapla. Actin was used as a positive control.

fig. 2a). No significant accumulation of cells in G1 and $\mathrm{G} 2 / \mathrm{M}$ phases was observed compared to the respective controls (data not shown). Inhibition of cell cycle progression was accompanied by induction of apoptosis, with a maximal increase following simultaneous treatment with zoledronic acid and paclitaxel. Simultaneous treatment with both agents increased apoptosis levels $(11.7 \pm 0.8 \%)$ compared to the untreated control $(0.6 \pm 0.06 \%$; $<<$ 0.001 ), the single agents (zoledronic acid: $2.2 \pm 0.3 \%$; paclitaxel: $6.2 \pm 0.5 \%$; $<<0.001)$ and to both sequential treatments (zoledronic acid followed by paclitaxel: $8.5 \pm$ 0.5\%; paclitaxel then zoledronic acid: $7.2 \pm 0.9 \%$; $<<$ 0.001; fig. 2b).

\section{Zoledronic Acid Inhibits Rapla Prenylation in HuDMEC}

Zoledronic acid acts by inhibition of farnesyl diphosphate synthase, a key enzyme in the mevalonate pathway, blocking prenylation of small GTPases, e.g. Rapla [21], causing intracellular accumulation of their unprenylated forms [22, 23]. Detection of increased levels of unprenylated Rapla is therefore commonly used as a surrogate measurement of zoledronic acid uptake by cells in vitro. The levels of unprenylated Rapla were determined fol- lowing 24-72 h of zoledronic acid treatment (fig. 3). Zoledronic acid increased accumulation of unprenylated Rapla in HuDMEC following exposure to 25 or $50 \mu \mathrm{M}$ for $24 \mathrm{~h}$, with further increases following 48 and $72 \mathrm{~h}$ of exposure.

\section{Combining Zoledronic Acid and Paclitaxel Causes Increased Inhibition of HuDMEC Tube Formation}

We used the Matrigel assay to investigate whether exposing HuDMEC to zoledronic acid for short periods affected tubule formation in vitro; a 4-hour exposure to 50 $\mu \mathrm{M}$ attenuated tube formation at $48 \mathrm{~h}$, reducing tubule number to $36.2 \pm 8.6 \%$ of control. Low doses of paclitaxel for $24 \mathrm{~h}$ reduced tubule number to $53.3 \pm 6.7$ (p $<$ $0.05)$ and $54.3 \pm 11.1 \%(\mathrm{p}<0.05)$ following treatment with 0.5 and $1 \mathrm{nM}$, respectively, compared to untreated control (data not shown). Using either single agents or drug combinations we demonstrated that $0.5 \mathrm{nM}$ of paclitaxel significantly inhibited tubule formation compared to control when given either before $(35.5 \pm 5.33$ vs. $0.8 \pm 4.6 \%, \mathrm{p}<0.01)$ or after $10 \mu \mathrm{M}$ of zoledronic acid $(41.0 \pm 6.6$ vs. $0.8 \% \pm 4.6 \%, p<0.001)$, which was not further enhanced by changing the drug sequence (fig. 4). In contrast, when both agents were given simultaneously, tubule number was reduced by $78.6 \pm 1.5 \%$ compared to control, both single-agent $(\mathrm{p}<0.001)$ and sequential treatments $(\mathrm{p}<0.001)$. In contrast to previous studies in breast cancer cells [14], the most effective combination of paclitaxel and zoledronic acid in EC appears to be simultaneous exposure to the two drugs.

\section{Combining Zoledronic Acid and Paclitaxel Causes Increased Inhibition of HuDMEC Migration}

Migration of EC is one of the fundamental processes occurring during angiogenesis, and several studies have reported significant inhibition of HUVEC migration by zoledronic acid $[9,18,28]$. Paclitaxel (5-20 nM) has also been shown to cause inhibition of chemotactic migration of human aortic EC [24]. We therefore investigated whether combining zoledronic acid and paclitaxel induced increased inhibition of EC migration compared to the single agents. Treatment with $50 \mu \mathrm{M}$ zoledronic acid or paclitaxel $0.5 \mathrm{nM}$ for $48 \mathrm{~h}$ did not significantly affect HuDMEC migration compared to untreated control (zoledronic acid $41.3 \pm 3.7$ vs. $52.9 \pm 3.0 \%$, and paclitaxel $49.6 \pm 5.6$ vs. $52.9 \pm 3.0 \%$; both $p>0.05$ ). In contrast, zoledronic acid combined with paclitaxel significantly inhibited migration compared to control (32.98 \pm 5.6 vs. $52.9 \pm 3.0 \%$; $p<0.01$; fig. 5). 


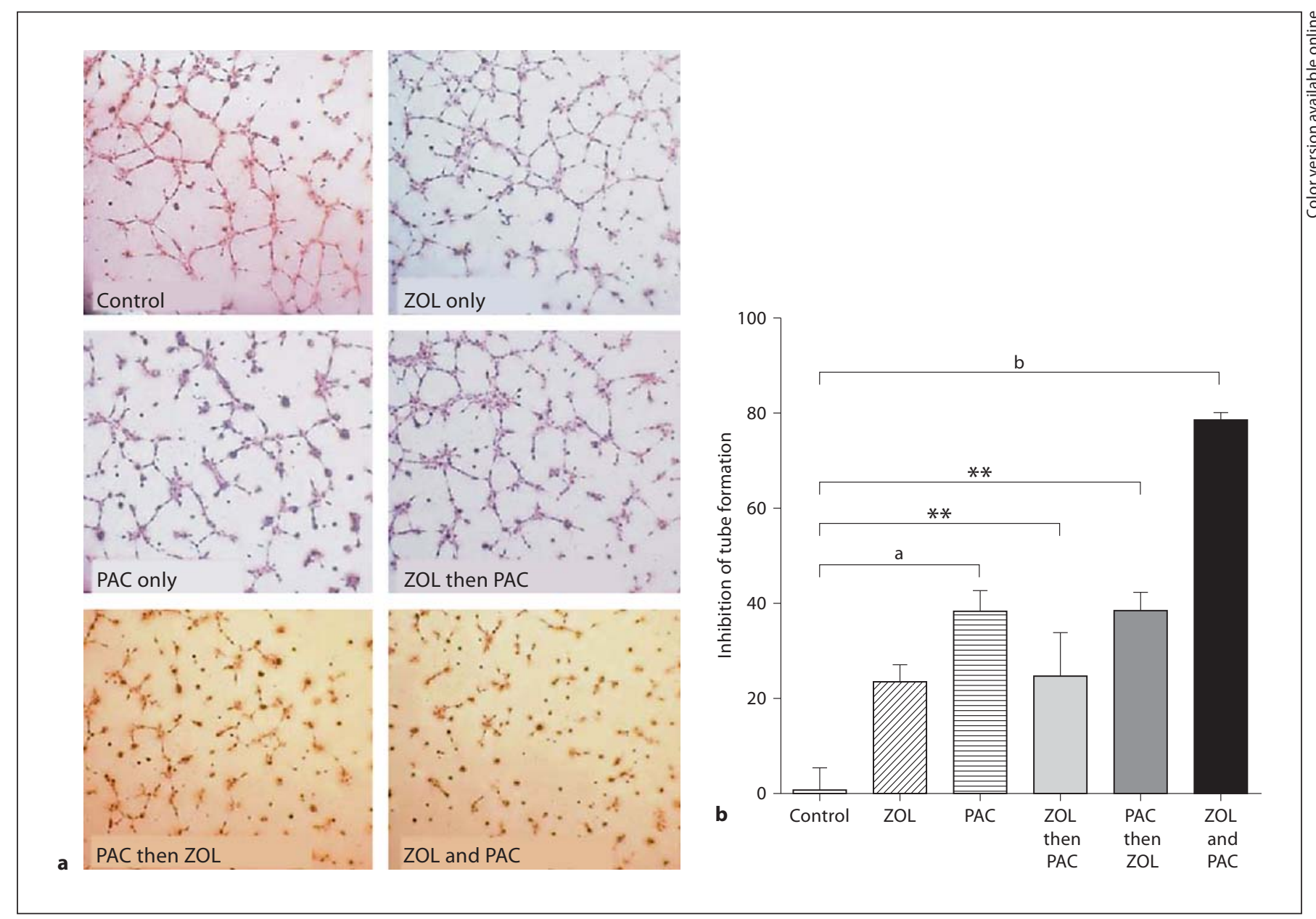

Fig. 4. The effect of combined treatment with zoledronic acid (ZOL) and paclitaxel (PAC) on HuDMEC tube formation. HuDMEC were pre-treated with $10 \mu \mathrm{M}$ zoledronic acid and 0.25 $\mathrm{nM}$ paclitaxel for $4 \mathrm{~h}$ with a 48 -hour incubation in drug-free medium, followed by incubation on full growth factor Matrigel for 8 h. a Representative views of tubular network (magnification: $\times 4)$. Scale bar: $25 \mu \mathrm{m}$. b Percentage inhibition of tube formation normalised against control. Error bars indicate \pm SEM $(n=3)$. ${ }^{* *} \mathrm{p}<0.01 ;{ }^{\mathrm{a}} \mathrm{p}<0.01$ or ${ }^{\mathrm{a}} \mathrm{p}<0.001$ vs. respective single-agent treatments; ${ }^{b}$ p $<0.001$ vs. untreated control, single-agent and combination treatments.

ministered to patients with skeletal complications associated with metastatic breast cancer [8]. Increasing doses of zoledronic acid did not significantly modulate venular (fig. 6) or arteriolar diameters compared to the baseline [on day $1(106.9 \pm 9.1$ vs. $99.6 \pm 8.8 \mu \mathrm{m})$, day 3 (98.91 \pm 0.4 vs. $90.5 \pm 9.8 \mu \mathrm{m})$ or day $5(96.8 \pm 9.6$ vs. $97.7 \pm$ $10.5 \mu \mathrm{m})$, baseline vs. $120 \mathrm{~min}$, respectively, each day of study (1, 3 and 5)]. Paclitaxel at increasing doses from 10 $\mathrm{mg} / \mathrm{kg}$ did not modulate venular diameters (fig. 6). Arteriolar diameter on day $1(10 \mathrm{mg} / \mathrm{kg})$, day $3(20 \mathrm{mg} / \mathrm{kg})$ and day $5(30 \mathrm{mg} / \mathrm{kg})$ demonstrated no significant differences between baseline and 120-min readings following paclitaxel treatment (baseline vs. $120 \mathrm{~min}$ : day 1, 


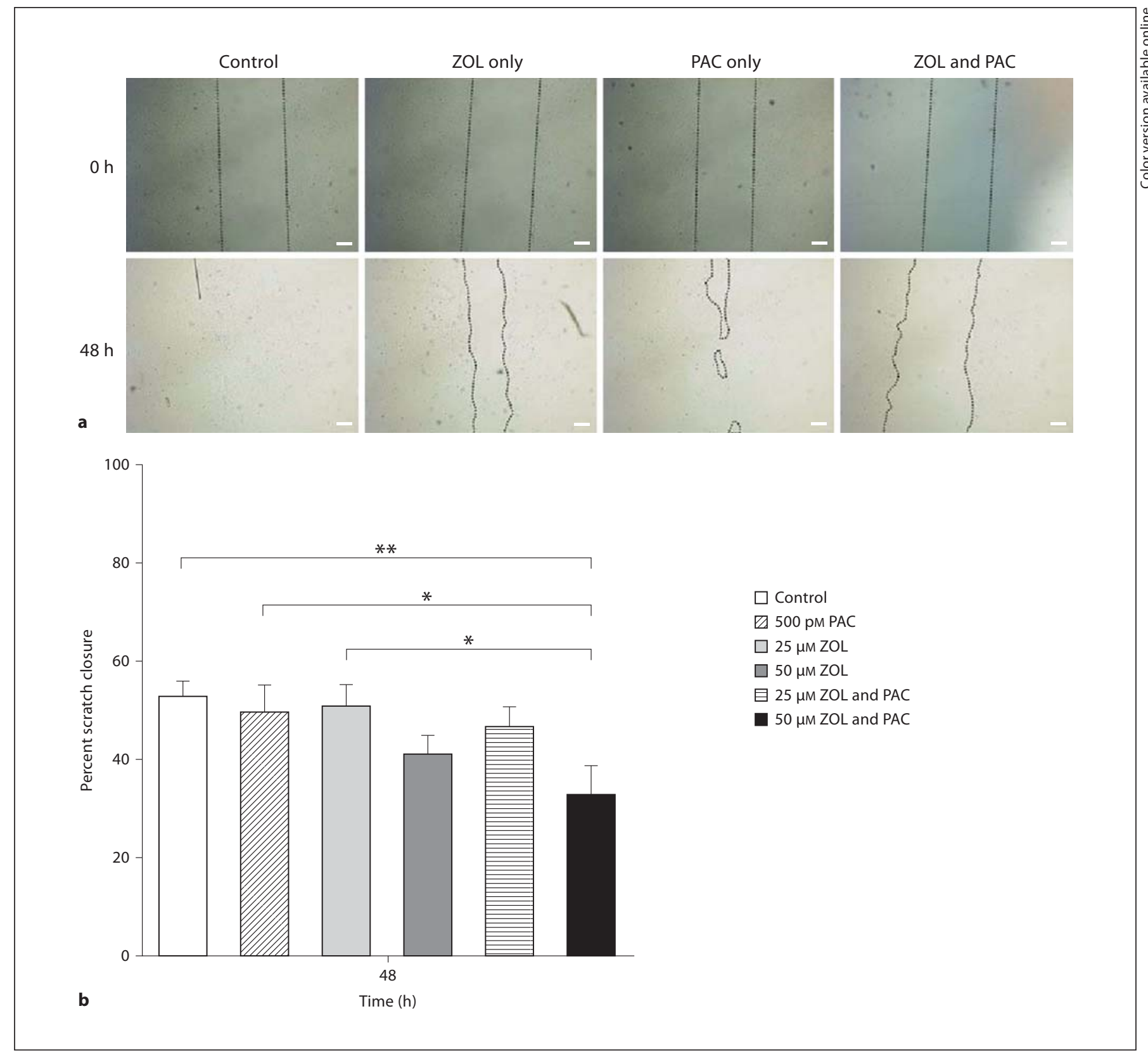

Fig. 5. The effect of combined treatment with zoledronic acid and paclitaxel on migration of HuDMEC. The cells were incubated with 25 and $50 \mu \mathrm{M}$ zoledronic acid and $500 \mathrm{pM}$ paclitaxel in standard culture medium for $48 \mathrm{~h}$. a Representative views of exposed endothelium immediately after scratch was produced $(0 \mathrm{~h})$ and then $48 \mathrm{~h}$ following treatment (magnification: $\times 10$ ). Scale bar: 25 $\mu \mathrm{m}$. b Representative example of data normalised against untreated control at $0 \mathrm{~h}$ and presented as percentage of scratch closure. ${ }^{*} \mathrm{p}<0.05,{ }^{* *} \mathrm{p}<0.01$. Error bars indicate $\pm \operatorname{SEM}(\mathrm{n}=3)$.
$104.2 \pm 15.2$ vs. $101 \pm 15.7 \mu \mathrm{m}$; day $3,83.1 \pm 14$ vs. 82.5 $\pm 11.4 \mu \mathrm{m}$, and day $5,85.4 \pm 18$ vs. $79.9 \pm 16.6 \mu \mathrm{m})$. There was a transient but significant $(\mathrm{p}<0.01)$ decrease in arteriolar diameter at both the 0 - and 120-minute time points between the high (day $5,30 \mathrm{mg} / \mathrm{kg}$ ) and the low (day $1,10 \mathrm{mg} / \mathrm{kg}$ ) paclitaxel concentrations. When zoledronic acid $(100 \mathrm{mg} / \mathrm{kg})$, was combined with paclitaxel $(20 \mathrm{mg} / \mathrm{kg})$, there were no significant changes in venular (fig. 6) or arteriolar diameters either acutely or over the 5-day experimental evaluation (day 1 vs. day 3 


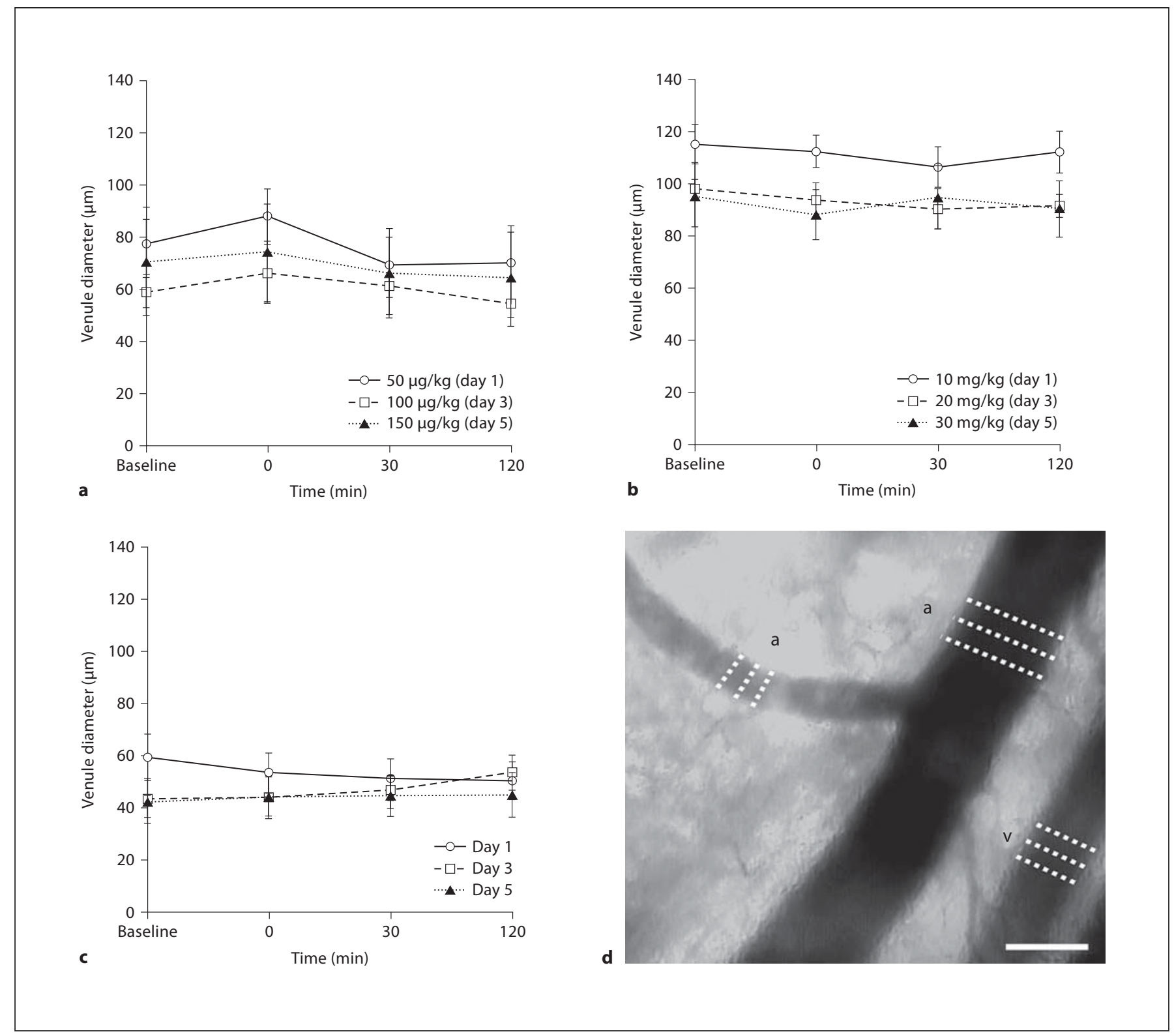

Fig. 6. The effect of zoledronic acid or paclitaxel alone and in combination on normal vessel diameters in CD1 nude mice. Vessel diameters were determined 0,30 and 120 min following administration of treatments on days 1,3 and 5. Data at each time point were normalised against the diameter at baseline on days 1, 3 and 5 . Data are presented as means \pm SEM. Venular diameter follow- ing zoledronic acid administration $(\mathbf{a} ; \mathrm{n}=8)$, paclitaxel administration $(\mathbf{b} ; \mathrm{n}=5)$ and following combination treatment $(\mathbf{c} ; \mathrm{n}=6)$. d Schematic representation of calculation of vessel diameter by Capiscope ${ }^{\circledR}$ software. Vessel diameters [arteriole (a) and venule (v)] were determined in triplicate per vessel $(---)$. Scale bar: $50 \mu \mathrm{M}$. vs. day $5,72.0 \pm 7.2$ vs. $60.9 \pm 8.5$ vs. $52.3 \pm 8.5 \mu \mathrm{m})$. There was no morbidity associated with any of the treatment schedules.

We also determined whether any of the treatments caused overt disruption of EC barriers or acute toxicity, by tissue morphology and microvascular architecture following treatment assessed in a separate experiment. Following resection and processing, histological assessment of the spleen, liver, lung and brain of tissue from animals in each treatment group was carried out by an 
Fig. 7. The effect of treatment with zoledronic acid or paclitaxel on spleen vasculature. CD1 nude mice were treated with saline, $100 \mu \mathrm{g} / \mathrm{kg}$ i.p. zoledronic acid 20 $\mathrm{mg} / \mathrm{kg}$ i.v. paclitaxel, alone or in combination. Animals were sacrificed and the spleen isolated and processed for histological analysis of the vasculature following staining with an antibody to CD34. a Control. b Paclitaxel only. c Zoledronic acid only. d Paclitaxel and zoledronic acid.
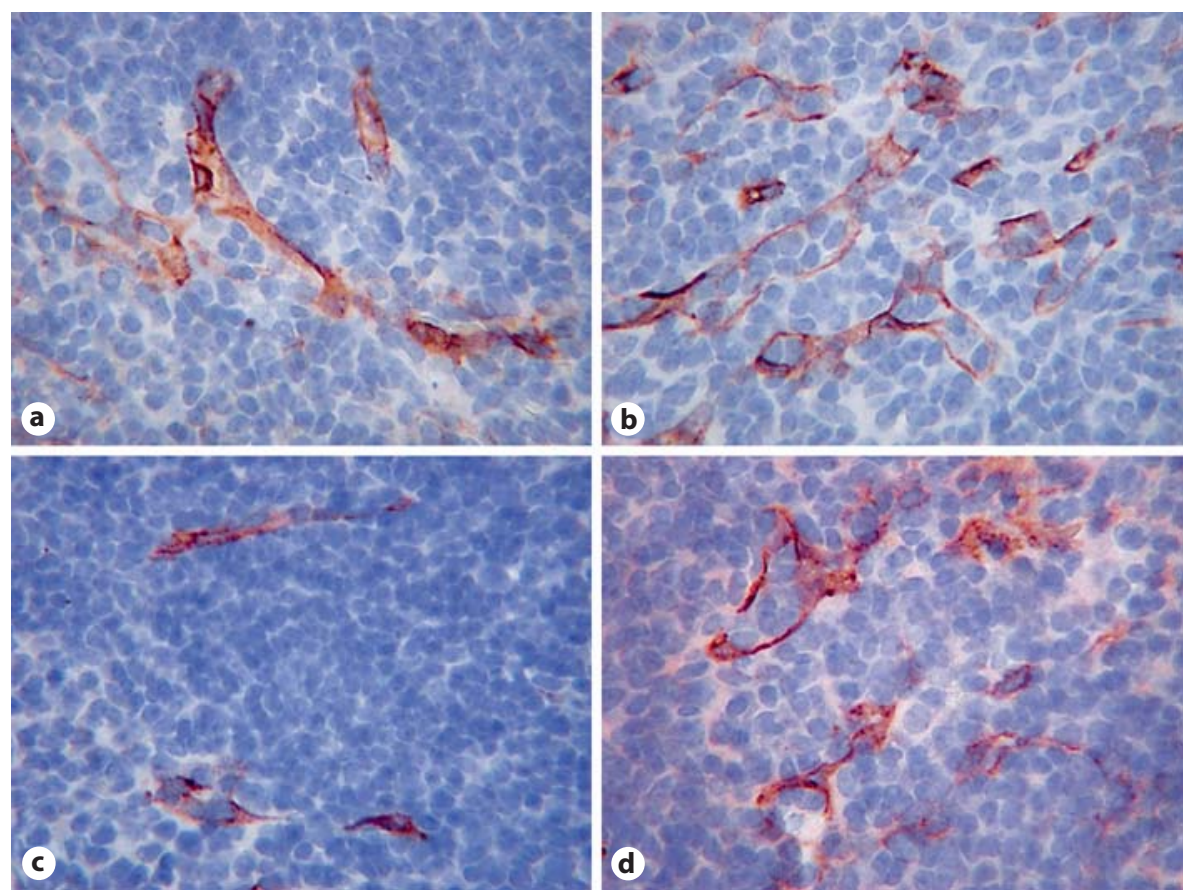

experienced histopathologist. No disruption of the endothelial barrier or tissue architecture was observed in any of the treatment groups (fig. 7).

\section{Discussion}

Treatment of cancer frequently involves a combination of different agents, some of which target the tumour vasculature, to eradicate tumour growth and progression. In vitro studies using tumour cell lines have shown that combination treatment with zoledronic acid and cytotoxic agents, including paclitaxel, results in increased anti-tumour effects compared to the single agents $[13,14$, 25]. These responses are seen at lower doses when drugs are used in combination in vitro, which may ultimately induce fewer or less severe side-effects in vivo. In addition, drugs may have unexpected adverse effects when given in combination, causing systemic toxicity or affecting normal tissue in addition to the tumour $[26,27]$. Prior to combining agents for therapeutic use, it is therefore important to determine the effects on both tumour cells and the normal cell types likely to be affected, both in vitro and in vivo. Although the anti-resorptive agent zoledronic acid is used extensively in the treatment of advanced cancers (including breast cancer), few studies have focused on the potential anti-angiogenic effects of this drug $[9,11]$, despite evidence that zoledronic acid modulates responses to EC in vitro $[9,10]$. Patients receiving zoledronic acid may also be receiving chemotherapy, including paclitaxel, but the consequence of the combination on the normal microvasculature or indeed the tumour microvascular network has not been described. To our knowledge this is the first study to focus on any endothelial-related events and aimed to determine whether combining paclitaxel and zoledronic acid increased antiangiogenic responses in vitro and/or caused adverse effects on the normal microvasculature in vivo.

Previous studies have shown that zoledronic acid inhibits HUVEC proliferation $[9,10]$ causing S-phase cell cycle arrest accompanied by increased levels of apoptosis [9]. Zoledronic acid also causes S-phase accumulation of a range of different tumour cell types [14, 23], which is associated with changes in cyclin expression and upregulation of cyclin-related kinase inhibitors [23], indicating specific effects on cell cycle progression. Reported dosing ranges and incubation times affecting HUVEC proliferation vary from 3-30 $\mu \mathrm{M}$ zoledronic acid for $24 \mathrm{~h}$ [9] to 100

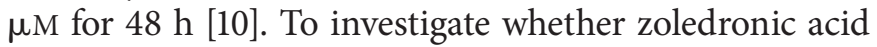
modulates proliferation of microvascular EC, HuDMEC were exposed to increasing doses of zoledronic acid for up to $72 \mathrm{~h}$. Zoledronic acid at $50 \mu \mathrm{M}$ inhibited HuDMEC proliferation after $24 \mathrm{~h}$, and this effect was further enhanced after 48 and $72 \mathrm{~h}$. Inhibition of cell proliferation was ac- 
companied by an accumulation of cells in $\mathrm{S}$ phase of the cell cycle after 48 and $72 \mathrm{~h}$. There was no evidence of apoptotic EC death, suggesting that zoledronic acid affects cell cycle progression via an apoptosis-independent pathway. The data suggest that the agents induce EC cytostasis without killing the cells, supporting previous studies showing that high doses of zoledronic acid $[9,28]$ and paclitaxel [17] are required for induction of apoptotic cell death. An apoptosis-independent mechanism of action has previously been described in cancer cell lines [29], which does not appear to be tumour cell specific, with similar results demonstrated in leukemic and colorectal carcinoma cell lines of wild-type p53 and p53-negative status [30]. In the current study, treatment with paclitaxel demonstrated that prolonged incubation periods $(72 \mathrm{~h})$ and high doses (10 $\mathrm{nM})$ were required to modulate HuDMEC proliferation. The same dose of paclitaxel was previously found to significantly inhibit HUVEC proliferation after only $24 \mathrm{~h}$ of treatment [20], which suggests a difference in sensitivity between macro- and microvascular EC. The reasons for this difference remain to be identified but could relate to a differential proliferation rate and/or uptake of the drug [31]. In support of this we found that at $48 \mathrm{~h}, 10 \mu \mathrm{M}$ zoledronic acid caused accumulation of unprenylated Rapla in HUVEC (data not shown), whereas in HuDMEC, this was only detectable following exposure to $25 \mu \mathrm{M}$. This is the first study showing that HuDMEC internalise zoledronic acid, causing accumulation of unprenylated Rapla in a dose- and time-dependent manner. Our main finding is that a high zoledronic acid dose $(50 \mu \mathrm{M})$ is required to modulate prenylation by $24 \mathrm{~h}$. In comparison, studies in tumour cells have shown accumulation of unprenylated Rapla following exposure to lower doses of zoledronic acid $[32,33]$, probably reflecting their higher endocytic activity and hence likely increased rate of drug uptake. The function of Rapla in EC remains to be established, and we have no evidence to suggest that there is a link between accumulation of unprenylated forms of this protein and inhibition of any of the in vitro angiogenic processes investigated. With a large number of cellular proteins undergoing post-translational prenylation [34], inhibition of this process by zoledronic acid is likely to affect a number of key molecules resulting in a range of cellular responses.

Previous studies have shown that the effects of zoledronic acid on breast cancer cell lines are enhanced by addition of a chemotherapeutic agent in a sequence-specific manner $[14,25,35]$. In the current study we therefore used the cytotoxic agent paclitaxel in combination with zoledronic acid to target HuDMEC, administering the drugs either in sequence or simultaneously. Our data show that compared to treatment with single agents, the combinations cause increased accumulation of cells in S phase and failure of $\mathrm{HuDMEC}$ to form tubules on Matrigel. In breast cancer cells the highest levels of apoptosis were induced by treatment with the cytotoxic agent prior to zoledronic acid [14], whereas in EC, simultaneous drug treatment was more effective than any of the sequential treatments. This differential EC and tumour cell response may be due to the targeting of different signalling pathways in addition to variations in the rate of drug uptake. Variations in treatment-induced HuDMEC sensitivity were evident, and were dependent on the functional process under investigation. Zoledronic acid and paclitaxel, both alone and in combination, disrupted basic EC functions, modulating the cytoskeletal-dependent processes of tubule formation and migration following $24 \mathrm{~h}$ of exposure, with tubule formation demonstrating an enhanced sensitivity to the combination regime. Cell viability, proliferation or cell cycle progression was less sensitive to the treatments. Breast cancer cells have previously been shown to demonstrate increased sensitivity to sequential drug exposure (paclitaxel followed by zoledronic acid) [14], whereas, in contrast, increased inhibition of tubule formation was seen following simultaneous drug exposure, thus highlighting the differential responses exhibited by different cell types.

The molecular mechanisms involved remain to be identified, although rapidly proliferating cancer cells with high metabolic activity are likely to have a different rate of drug uptake compared to EC. The dose of $100 \mu \mathrm{M}$ zoledronic acid which inhibited EC migration is high compared to that achievable in the clinical setting (serum levels of maximally $1-2 \mu \mathrm{M}$ for $1-2 \mathrm{~h}$ following the standard 4-mg infusion), and therefore is unlikely to affect EC during standard patient therapy. However, there are no corresponding published data regarding the effects of zoledronic acid on microvascular EC migration like HuDMEC. Paclitaxel (10 pM) has been shown to inhibit migration of HUVEC through Matrigel membranes in vitro [16], whereas later similar studies report variable effects using doses ranging from 0.1 to $10 \mathrm{nM}[20,36]$.

Having found that combined treatment with paclitaxel and zoledronic acid modulated a number of processes involved in angiogenesis in vitro, we next studied the effects of these drugs, alone and in combination, on the normal microvasculature in DMC in vivo. Both paclitaxel [37-39] and zoledronic acid [5, 7, 8, 40] demonstrate anti-tumour growth effects in vivo, and further investigation has established zoledronic acid is anti-angiogenic in non-tumour models in vivo. Previous studies reported a 35\% reduction in prostate weight in testosterone-treated 
castrated rats compared to controls following subcutaneous administration of $20 \mu \mathrm{g} / \mathrm{kg} /$ day zoledronic acid [10], which was due to inhibition of testosterone-induced vascularisation of the ventral prostate. In addition to bone, bisphosphonates also accumulate in the prostate, probably due to the high concentration of zinc, which may increase specific targeting of prostatic vascularisation. Another study reported that daily administration of 10 and $100 \mu \mathrm{g} / \mathrm{kg}$ zoledronic acid for 6 days inhibited angiogenesis induced by basic fibroblast and vascular endothelial growth factor in a growth factor implant model of angiogenesis in mice [9]. In agreement with this study, we found that high and prolonged dosing with zoledronic acid was required to reduce HuDMEC proliferation in vitro. Anti-angiogenic properties of paclitaxel have been demonstrated in pre-coated stents, with a dose-dependent inhibition of neointimal hyperplasia, accompanied by a reduction in the mean luminal diameter in the stented segment reported [41]. In addition, a significant reduction in the haemoglobin content of subcutaneous Matrigel pellets has been demonstrated following administration of $28 \mathrm{mg} / \mathrm{kg}$ paclitaxel, but not with $10 \mathrm{mg} / \mathrm{kg}$ [16].

In the current study, the DMC model was used to determine any treatment-induced responses of the normal, established, quiescent microvasculature, which may be less sensitive to the therapeutic agents than vessels undergoing endothelial proliferation. Zoledronic acid was administered between 50 and $150 \mu \mathrm{g} / \mathrm{kg}$, as $100 \mu \mathrm{g} / \mathrm{kg}$ is the standard used in in vivo tumour models and is equivalent to the 4-mg clinical dose [8]. Increasing doses of zoledronic acid did not modulate basal arteriolar or venular diameters, whereas increasing doses of paclitaxel demonstrated small transient decreases in arteriolar diameters in a proportion of vessels. The combination of $100 \mu \mathrm{g} / \mathrm{kg}$ zoledronic acid with $20 \mathrm{mg} / \mathrm{kg}$ paclitaxel had no significant effects on arteriolar or venular diameters on days 1 , 3 and 5 of treatment. No treatment morbidity was observed. Histological assessment revealed normal microvascular and tissue morphology and architecture in skeletal muscles, brain, spleen, lungs and liver.

Any successful anti-angiogenic/anti-vascular therapy must mainly target the proliferating tumour microvasculature, whilst inducing minimal disruption to the normal vessels. It is therefore of crucial importance to determine whether combining potent anti-cancer agents results in structural or functional disruption of the healthy microvasculature. To our knowledge, this is the first study to investigate any early responses (up to 5 days) on the normal microvasculature in vivo using paclitaxel and/or zoledronic acid. Our data show that the combination of paclitaxel and zoledronic acid modulates proliferating EC in vitro, but high concentrations and prolonged exposure times are required to initiate significant inhibition. In contrast, combined treatment with clinically achievable doses of both agents did not induce acute $(2 \mathrm{~h})$ or short-term responses (up to 5 days) in the normal quiescent microvasculature in the DMC in vivo. The normal tissue architecture and different cell types in a physiological in vivo microenvironment may influence the availability, binding and uptake of paclitaxel and zoledronic acid, when compared to the single cell type in vitro models where combined effects of the drugs were demonstrated. Further studies determining responses to prolonged drug treatment in tumour models in vivo will identify whether this combination regime demonstrates potential therapeutic efficacy.

\section{Acknowledgements}

The authors wish to acknowledge Novartis Pharma AG (Basel, Switzerland) for kindly providing zoledronic acid. This study was supported by the Breast Cancer Campaign (UK) and the Linda and Michael Jacobs Charitable Trust (UK). We thank Prof. M.W.R. Reed for providing adipose tissue specimens for HuDMEC isolation and Dr. Lynne Bingle for demonstrating the surgical procedure for DMC implantation.

References

$>1$ Ng SSW, Figg WD, Sparreboom A: Taxanemediated antiangiogenesis in vitro: influence of formulation vehicles and binding proteins. Cancer Res 2004;64:821-824.

-2 Albertsson P, Lennernas B, Norrby K: Chemotherapy and antiangiogenesis: drugspecific effects on microvessel sprouting. APMIS 2003;111:995-1003.

- 3 Pasquier E, Honore S, Pourroy B, Jordan MA, Lehmann M, Briand C, Braguer D: Antiangiogenic concentrations of paclitaxel induce an increase in microtubule dynamics in endothelial cells but not in cancer cells. Cancer Res 2005;65:2433-2440.

-4 Lennernaes B, Albertsson P, Lennernaaes H, Norrby K: Chemotherapy and antiangiogenesis: drug-specific, dose-related effects. Acta Oncol 2003;42:294-303.

$\checkmark 5$ Green JR: Antitumour effects of bisphosphonates (review). Cancer 2003;97(suppl): 840-847.

6 Coleman RE: Bisphosphonates in breast cancer. Ann Oncol 2005;16:687-695.

$\checkmark 7$ Hiraga T, Williams PJ, Ueda A, Tamura D, Yoneda T: Zoledronic acid inhibits visceral metastases in the $4 \mathrm{~T} 1 /$ luc mouse breast cancer model. Clin Cancer Res 2004;10:4559-4567.

Michailidou/Brown/Lefley/Evans/Cross/ Coleman/Brown/Holen 
-8 Daubiné F, Le Gall C, Gasser J, Green J, Clézardin P: Antitumor effects of clinical dosing regimens of bisphosphonates in experimental breast cancer bone metastasis. J Natl Cancer Inst 2007;99:322-330.

-9 Wood J, Bonjean K, Ruetz S, Bellahcene A, Devy L, Foidart JM, Castronovo V, Green JR: Novel antiangiogenic effects of the bisphosphonate compound zoledronic acid. J Pharmacol Exp Ther 2002;302:1055-1061.

-10 Fournier P, Boissier S, Filleur S, Guglielmi J, Cabon F, Colombel M, Clezardin P: Bisphosphonates inhibit angiogenesis in vitro and testosterone-stimulated vascular regrowth in the ventral prostate in castrated rats. Cancer Res 2002;62:6538-6544.

-11 Santini D, Vincenzi B, Dicuonzo G, Avvisati G, Massacesi C, Battistoni F, Gavasci M, Rocci L, Tirindelli MC, Altomare V, Tocchini M, Bonsignori M, Tonini G: Zoledronic acid induces significant and long-lasting modifications of circulating angiogenic factors in cancer patients. Clin Cancer Res 2003;9:2893-2897.

-12 Zimering MB: Effect of intravenous bisphosphonates on release of basic fibroblast growth factor in serum of patients with cancer-associated hypercalcemia. Life Sci 2002; 70:1947-1960.

-13 Jagdev SP, Coleman RE, Shipman CM, Rostami-H A, Croucher PI: The bisphosphonate, zoledronic acid, induces apoptosis of breast cancer cells: evidence for synergy with paclitaxel. Br J Cancer 2001;84:1126-1134.

-14 Neville-Webbe HL, Evans CA, Coleman RE, Holen I: Mechanisms of the synergistic interaction between the bisphosphonate zoledronic acid and the chemotherapy agent paclitaxel in breast cancer cells in vitro. Tumor Biol 2006;27:92-103.

-15 Nogales E, Wolf S, Khan I, Ludueña R, Downing K: Structure of tubulin at $6.5 \mathrm{~A}$ and location of the Taxol-binding site. Nature 1995; 75:424-427.

16 Belotti D, Vergani V, Drudis T, Borsotti P, Pitelli MR, Viale G, Giavazzi R, Taraboletti G: The microtubule-affecting drug paclitaxel has antiangiogenic activity. Clin Cancer Res 1996;2:1843-1849.

-17 Pasquier E, Carre M, Pourroy B, Camoin L, Rebaï O, Briand C, Braguer D: Antiangiogenic activity of paclitaxel is associated with its cytostatic effect, mediated by the initiation but not completion of a mitochondrial apoptotic signaling pathway. Mol Cancer Ther 2004;3:1301-1310.

- 18 Bezzi M, Hasmim M, Bieler G, Dormond O, Ruegg C: Zoledronate sensitizes endothelial cells to tumor necrosis factor-induced programmed cell death: evidence for the suppression of sustained activation of focal adhesion kinase and protein kinase B/Akt. J Biol Chem 2003;278:43603-43614.
19 Bingle L, Lewis CE, Corke KP, Reed MWR, Brown NJ: Macrophages promote angiogenesis in human breast tumour spheroids in vivo. Br J Cancer 2006;94:101-107.

20 Grant DS, Williams TL, Zahaczewsky M, Dicker AP: Comparison of antiangiogenic activities using paclitaxel (Taxol) and docetaxel (Taxotere). Int J Cancer 2003;104: 121-129.

-21 McTaggart S: Isoprenylated proteins. Cell Mol Life Sci 2006;63:255-267.

22 Coxon FP, Thompson K, Rogers MJ: Recent advances in understanding the mechanism of action of bisphosphonates. Curr Opin Pharmacol 2006;6:307-312.

23 Kubista B, Trieb K, Sevelda F, Toma C, Arrich F, Heffeter P, Elbling L, Sutterlüty $\mathrm{H}$, Scotlandi K, Kotz R, Micksche M, Berger W: Anticancer effects of zoledronic acid against human osteosarcoma cells. J Orthop Res 2006;24:1145-1152.

24 Davis HW, VandenBerg E, Reid MD, RoyChaudhury P, Edwards JD: Paclitaxel impairs endothelial cell adhesion but not cytokine-induced cellular adhesion molecule expression. Ann Vasc Surg 2005;19:398-406.

25 Neville-Webbe HL, Rostami-Hodjegan A, Evans CA, Coleman RE, Holen I: Sequenceand schedule-dependent enhancement of zoledronic acid induced apoptosis by doxorubicin in breast and prostate cancer cells. Int J Cancer 2005;113:364-371.

26 Bafaloukos D, Tsoutsos D, Kalofonos H, Chalkidou S, Panagiotou P, Linardou E, Briassoulis E, Efstathiou E, Polyzos A, Fountzilas G, Christodoulou C, Kouroussis C, Iconomou T, Gogas H: Temozolomide and cisplatin versus temozolomide in patients with advanced melanoma: a randomized phase II study of the Hellenic Cooperative Oncology Group. Ann Oncol 2005;16:950-957.

27 Hassett MJ, O’Malley AJ, Pakes JR, Newhouse JP, Earle CC: Frequency and cost of chemotherapy-related serious adverse effects in a population sample of women with breast cancer. J Natl Cancer Inst 2006;98: 1108-1117.

28 Hasmim M, Bieler G, Rüegg C: Zoledronate inhibits endothelial cell adhesion, migration and survival through the suppression of multiple, prenylation-dependent signalling pathways. J Thromb Haemost 2006;5:166173.

29 Ory B, Blanchard F, Battaglia S, Gouin F, Rédini F, Heymann D: Zoledronic acid activates the DNA S-phase checkpoint and induces osteosarcoma cell death characterized by apoptosis-inducing factor and endonuclease-G translocation independently of p53 and retinoblastoma status. Mol Pharmacol 2007;71:333-343.

-30 Kuroda J, Kimura S, Segawa H, Sato K, Matsumoto S, Nogawa M, Yuasa T, Kobayashi Y, Yoshikawa T, Ottmann OG, Maekawa T: p53-independent anti-tumor effects of the nitrogen-containing bisphosphonate zoledronic acid. Cancer Sci 2004;95:186-192.
31 Thompson K, Rogers M, Coxon F, Crockett $\mathrm{J}$ : Cytosolic entry of bisphosphonate drugs requires acidification of vesicles after fluidphase endocytosis. Mol Pharmacol 2006;69: 1624-1632.

32 Goffinet M, Thoulouzan M, Pradines A, Lajoie-Mazenc I, Weinbaum C, Faye J, SéronieVivien S: Zoledronic acid treatment impairs protein geranyl-geranylation for biological effects in prostatic cells. BMC Cancer 2006; 6:60.

33 Wakchoure S, Merrell MA, Aldrich W, Millender-Swain T, Harris KW, Triozzi P, Selander KS: Bisphosphonates inhibit the growth of mesothelioma cells in vitro and in vivo. Clin Cancer Res 2006;12:2862-2868.

34 Walker K, Olson MF: Targeting Ras and Rho GTPases as opportunities for cancer therapeutics. Curr Opin Genet Dev 2005;15:6268.

-35 Santini D, Caraglia M, Vincenzi B, Holen I, Scarpa S, Budillon A, Tonini G: Mechanisms of disease: preclinical reports of antineoplastic synergistic action of bisphosphonates. Nat Clin Pract Oncol 2006;3:325-338.

-36 Hotchkiss KA, Ashton AW, Mahmood R, Russell RG, Sparano JA, Schwartz EL: Inhibition of endothelial cell function in vitro and angiogenesis in vivo by docetaxel (Taxotere): association with impaired repositioning of the microtubule organizing center. Mol Cancer Ther 2002;1:1191-1200.

-37 Kubota T, Matsuzaki SW, Hoshiya Y, Watanabe M, Kitajima M, Asanuma F, Yamada Y, Koh JI: Antitumor activity of paclitaxel against human breast carcinoma xenografts serially transplanted into nude mice. J Surg Oncol 1997;64:115-121.

38 Milross CG, Mason KA, Hunter NR, Chung WK, Peters LJ, Milas L: Relationship of mitotic arrest and apoptosis to antitumor effect of paclitaxel. J Natl Cancer Inst 1996;88: 1308-1313.

-39 Zhang AL, Russell PJ: Paclitaxel suppresses the growth of primary prostate tumours (RM-1) and metastases in the lung in C57BL/6 mice. Cancer Lett 2006;233:185191.

40 Yoneda T, Michigami T, Yi B, Williams PJ, Niewolna M, Hiraga T: Actions of bisphosphonate on bone metastasis in animal models of breast carcinoma. Cancer 2000;88: 2979-2988.

41 Heldman AW, Cheng L, Jenkins GM, Heller PF, Kim DW, Ware M Jr, Nater C, Hruban RH, Rezai B, Abella BS, Bunge KE, Kinsella JL, Sollott SJ, Lakatta EG, Brinker JA, Hunter WL, Froehlich JP: Paclitaxel stent coating inhibits neointimal hyperplasia at 4 weeks in a porcine model of coronary restenosis. Circulation 2001;103:2289-2295. 